\title{
Poem
}

\section{The days are getting shorter}

I want to go sit in a park To look at the sparrows As they peck the eyes Out of the lawn

Sit alone to feel the touch Of the Gods I don't believe in Watch the Sun set slowly Through the eucalypts

I want to be an old man Thinking about those things He didn't do, with resignation But no regrets

\section{Cool dude haiku}

If you sit \& wait

With a full glass \& empty mind Solutions arise

\section{Uncool dude haiku}

If I tighten hands On the steering wheel \& grind My teeth - w-won't crash ...

\section{Dead dude haiku}

So it is shorter

To take the short cut along That rough dirt road - ski-d ...

\section{Dead duck haiku}

Ambulance sirens Somewhere - though not far away Another dead duck 